\title{
DIMENSIONAMENTO DO QUADRO DE PESSOAL DO HOSPITAL MUNICIPAL, AMBULATÓRIO E UPA DO MUNICÍPIO DE ARAGUAÍNA - TO
}

\section{ARTIGO ORIGINAL}

SILVA, Carlos Eduardo Gomes Da ${ }^{1}$

SILVA, Carlos Eduardo Gomes Da. Dimensionamento do quadro de pessoal do hospital municipal, Ambulatório e UPA do Município de Araguaína - TO. Revista Científica Multidisciplinar Núcleo do Conhecimento. Ano 04, Ed. 11, Vol. 01, pp. 145167. Novembro de 2019. ISSN: 2448-0959, Link de acesso: https://www.nucleodoconhecimento.com.br/saude/hospital-municipal

\section{RESUMO}

O presente trabalho busca discutir sobre a redução de custos no quadro de pessoal do Hospital Municipal a partir do Ambulatório de Especialidades e das Unidades de Pronto Atendimento da saúde pública oferecida aos usuários do Sistema Único de Saúde - SUS do município de Araguaína-TO e região a partir da parceria feita entre o município e uma Organização Social (OS). Entre os questionamentos que o presente o estudo busca está a seguinte questão: será que é possível oferecer melhor qualidade num serviço tão essencial à comunidade gastando-se menos recursos? Como medir a produtividade de um serviço tão complexo quanto a própria área da saúde sendo ela pública ou privada? Dessa forma, realizaremos um diagnóstico acerca da situação atual, buscando, assim, responder se é possível reduzir custos

\footnotetext{
1 Pós-graduado no MBA Gestão De Negócios, Controladoria E Finanças Corporativas pelo Instituto de Pós-Graduação e Graduação (IPOG); Pós-graduado em Formação De Professores Em Didática E Gestão Educacional pelo Instituto de Pós-Graduação e Graduação (IPOG); Pós-Graduado em Gestão Pública Municipal pela Universidade Estadual de Goiás (UEG) e Bacharel em Administração pelo Instituto de PósGraduação e Graduação (IPOG).
} 
sem comprometer a eficiência do processo. Para tanto, a metodologia utilizada foi a pesquisa descritiva exploratória na modalidade de estudo de caso. Os dados foram coletados por meio de visita técnica feitas in-loco, por meio de entrevistas semiestruturadas, reuniões e observações que foram confrontadas com o levantamento da literatura técnica existente. Os resultados obtidos indicam, num primeiro momento, o dimensionamento do quadro de colaboradores das unidades seguido da proposta de redimensionamento dentro dos parâmetros utilizados visando a reeducação de custo sem a perda da qualidade dos serviços.

Palavras-chave: Redução de custo, redimensionamento de pessoal, saúde.

\section{INTRODUÇÃO}

Em meio a um cenário empresarial cada vez mais competitivo, os gestores das organizações se deparam, diariamente, com a necessidade de instrumentos gerenciais que o auxiliem na administração dos recursos disponíveis na consecução das atividades operacionais. Não obstante deste contexto, também se enquadram as instituições de saúde que, geralmente, pelo seu caráter essencial, passa quase que imperceptível pelo quesito da competitividade. Uma vez que as mesmas competem amplamente no mesmo cenário onde outras organizações buscam, com muito esforço, sua perpetuação e/ou simplesmente a garantia de sua própria existência. Sobre o assunto, muito bem esclarece Matos (2005) quando diz: “...as empresas desse segmento empresarial convivem com os mesmos desafios de uma crescente demanda de gestão profissional, sem a qual não se conseguirá a viabilização das organizações de saúde, para não dizer da própria manutenção da sobrevivência" (MATOS, 2005, p. 19).

É neste cenário desafiador da saúde pública no Brasil que o presente estudo pretende contribuir. Para isso, busca soluções para um dos problemas mais desafiadores de qualquer organização, a saber, a gestão dos recursos cada vez mais escassos, sejam estes recursos materiais, financeiros ou humanos. Originalmente, o presente estudo foi realizado a pedido de uma Organização Social (O.S.) que celebra um contrato de gestão junto ao Município de Araguaína em três unidades Sistema Único de Saúde 
municipal a saber: Hospital Municipal de Araguaína (CNES ${ }^{[2]} n^{0}$ 3663051), Ambulário de Especialidades (CNES no 6216420) e Unidade de Pronto Atendimento (CNES no 6886345). Na busca pela otimização da gestão dos recursos humanos disponíveis surge logo o primeiro questionamento: é possível atender melhor a população que consome diariamente o serviço oferecido pelo município a partir da Organização Social empregando uma quantidade de recursos humanos menor que a disponível atualmente na estrutura organizacional?

Um dos fatores mais relevantes na busca desta resposta trata-se, exatamente, da complexidade da área do estudo. Por se tratar de uma área tão essencial ao indivíduo, não se deve aplicar qualquer técnica de redução ou otimização de recurso sem antes compreender o contexto, as implicações e o risco envolvido numa intervenção deste porte. Da mesma forma, o tema justifica-se, ainda, pela complexidade do assunto, ou seja, por sua relevância social, pois uma tomada de decisão deste porte atinge, diretamente, uma amostra muito expressiva da população. A fim de responder este tipo de questionamento, o presente artigo tem como objetivo geral identificar a possibilidade de otimizar o aproveitamento dos recursos humanos nas unidades de saúde administradas pela Organização Social (O.S.), por meio de contrato de gestão com o município de Araguaína-TO considerando os seguintes aspectos:

a) Analisar o atual dimensionamento do quadro de colaboradores das unidades de saúde administradas pela Organização Social junto ao município; e

b) Apresentar uma proposta de adequação do quadro.

Vale ressaltar que o principal agente atuante dentro deste processo é um modelo recente de gestão compartilhada. Nele, o poder público celebra uma parceria com instituições privadas, neste caso com as Organizações Sociais, também conhecidas como OS's. A fim de resgatar um passado muito próximo, devemos lembrar que, no Brasil, as organizações sociais surgiram em 15 de maio de 1998, regulamentadas pela Lei 9.637. Barbosa e Elias (2010), relatam que desde meados dos anos 1990, a expressão deste termo foi tomando força por meio do Plano Diretor de Reforma do Aparelho do Estado (PDRAE), proposto pelo Ministério da Administração e Reforma 
do Estado (Mare), ainda no primeiro governo FHC (1995-2002). As questões centrais deste debate permeavam a esfera da implantação de novas formas de gestão e provisão de serviços públicos na área dos serviços não exclusivos do Estado. De acordo com o PDRAE:

As Organizações Sociais em Saúde (OSSs) são definidas como entidades de interesse e de utilidade pública, associação sem fins lucrativos, surgidas da qualificação de pessoas jurídicas de direito privado, nas atividades de ensino, pesquisa tecnológica, desenvolvimento tecnológico, proteção e preservação do meio-ambiente (1990, p. 60).

Observa-se que o conceito acima trata, especificamente, das organizações sociais da área da saúde, tendo em vista que este foi o primeiro modelo implantado no Brasil, vindo depois para as outras áreas, e, por último, conforme amplamente divulgado nos meios de comunicação, as OS's migraram para a área da educação. Já para Ribeiro (2017), este conceito é ampliado e atinge um patamar mais filosófico definido por ele desta forma: "A ideia de organização social está ligada ao processo social, à ideia de mudança, de arranjo do comportamento dos indivíduos na construção da vida social." Findados os debates e evitando as controvérsias, o fato é que as Organizações Sociais estão cada dia mais presentes na administração pública, e, assim, ocupam as lacunas que o Estado não consegue preencher.

É exatamente em meio a este cenário que discorre o objeto de nosso estudo o qual será apresentado a partir de seu desenvolvimento apresentando, para tanto, reflexões sobre o dimensionamento do quatro atual de colaboradores. Este trabalho foi dividido partes, sendo que, na primeira, foram levantadas as características do Município de Araguaína em relação ao setor saúde. Na segunda, há a descrição da metodologia utilizada para o desenvolvimento da proposta de readequação do quadro de colaboradores. A terceira parte do estudo é composta por parâmetros e conceitos utilizados no presente trabalho e na quarta é feito um diagnóstico situacional das unidades de saúde objeto da pesquisa. Na última etapa foi apresentada a proposta de redimensionamento dentro dos parâmetros utilizados e, ao final, foram realizadas as considerações elencadas sobre as possíveis dificuldades que poderá haver na fase de implantação do dimensionamento proposto. 


\section{CONSIDERAÇÕES SOBRE O MUNICÍPIO DE ARAGUAÍNA}

O Município de Araguaína está localizado no Estado do Tocantins, na Região de Saúde Médio Norte Araguaia, com uma população de 170.183 habitantes (IBGE, 2015) e é referência para a população da Macrorregião Centro Norte, composta pelas Regiões de Saúde Bico do Papagaio, Médio Norte Araguaia e Cerrado Tocantins Araguaia, abrangendo uma população de 652.103 pessoas (IBGE 2015), o que corresponde a 43,03\% do total de habitantes do Estado. Em Araguaína existem 196 estabelecimentos de saúde registrados no Cadastro Nacional de Estabelecimentos de Saúde - CNES, do Ministério da Saúde, assim classificados:

Tabela 1 - Tipo de estabelecimentos de saúde

\begin{tabular}{|l|l|}
\hline Tipo de estabelecimento & Quantidade \\
\hline Hospital Geral & 4 \\
\hline Hospital especializado & 1 \\
\hline Consultórios médicos & 125 \\
\hline Pronto Atendimento & 1 \\
\hline Outros & 65 \\
\hline Total & $\mathbf{1 9 6}$ \\
\hline
\end{tabular}

Fonte: Ministério da Saúde, DATASUS, CNES, 2016

Os quatro hospitais gerais realizaram nos anos de 2015 e 2016, 20.385 e 9.032 internações, respectivamente, aprovadas pelo Sistema de Informações Hospitalares do SUS - SIH/SUS:

Tabela 2 - Número de internações hospitalares aprovadas por estabelecimento

\begin{tabular}{|l|l|l|}
\hline Estabelecimento & Ano \\
\hline Hospital Regional de Araguaína & $\mathbf{2 0 1 5}$ & $\mathbf{2 0 1 6 ^ { * }}$ \\
\hline Hospital Dom Orione de Araguaína & 8.924 & 3.554 \\
\hline
\end{tabular}




\begin{tabular}{|l|l|l|}
\hline HDT - Hospital de Doenças Tropicais de Tocantins & 1.226 & 651 \\
\hline Hospital Municipal de Araguaína & 2.242 & 963 \\
\hline Total & $\mathbf{2 0 . 3 8 5}$ & $\mathbf{9 . 0 3 2}$ \\
\hline
\end{tabular}

Fonte: Ministério da Saúde - Sistema de Informações Hospitalares do SUS (SIH/SUS), 2016 * até a competência jun/2016

Além das unidades hospitalares citada acima, as consultas médicas especializadas também são realizadas no Ambulatório de Especialidades e na Unidade de Pronto Atendimento. Totalizou-se o número de 181.507 e 62.999 de atendimentos nos anos de 2015 e 2016, respectivamente.

Tabela 3 - Número de consultas médicas especializadas aprovadas por estabelecimento

\begin{tabular}{|l|l|l|}
\hline Estabelecimento & Ano \\
\cline { 2 - 3 } & $\mathbf{2 0 1 5}$ & $\mathbf{2 0 1 6}^{\boldsymbol{*}}$ \\
\hline Instituto de Doenças Renais do Tocantins & 304 & 100 \\
\hline APAE de Araguaína & 706 & 506 \\
\hline Hemocentro Regional & 335 & 148 \\
\hline Hospital Regional de Araguaína & 46.227 & 11.704 \\
\hline Hospital Dom Orione de Araguaína & 3.083 & 1.730 \\
\hline HDT - Hospital de Doenças Tropicais de Tocantins & 16.051 & 7.695 \\
\hline Hospital Municipal de Araguaína & 1.214 & 370 \\
\hline Ambulatório de Especialidades & 11.857 & 7.445 \\
\hline UPA Anatólio Dias Carneiro & 101.730 & 33.301 \\
\hline Total & $\mathbf{1 8 1 . 5 0 7}$ & $\mathbf{6 2 . 9 9 9}$ \\
\hline
\end{tabular}

Fonte: Ministério da Saúde - Sistema de Informações Ambulatoriais do SUS (SIA/SUS), 2016* até a competência jun/2016.

As consultas médicas especializadas realizadas nas unidades de saúde administradas pela Organização Social correspondem a cerca de $64,25 \%$ do total de 
procedimentos realizados em Araguaína. O trânsito intraestadual de pacientes pode ser visualizado por meio do mapa de encaminhamento construído com base nos registros constantes nas Autorizações de Internação Hospitalar - AlHs com registro no DATASUS do Ministério da Saúde. Ao se analisar os dados do Estado de Tocantins é possível constar que o maior fluxo de pacientes é para as cidades de Araguaína e Palmas (figura 1), o que demonstra que a primeira é uma cidade polo no setor saúde, o que também reflete na composição dos recursos humanos disponíveis na cidade.

Tabela 4 - Quantidade de profissionais por profissão e local de atuação

\begin{tabular}{|l|l|l|l|}
\hline \multirow{2}{*}{ Profissão } & \multicolumn{3}{c}{ Quantidade de profissionais* } \\
\cline { 2 - 4 } & Tocantins & Araguaína & $\%$ em Araguaína \\
\hline Assistente social & 438 & 51 & $11,64 \%$ \\
\hline Enfermeira & 2320 & 427 & $18,41 \%$ \\
\hline Farmacêutico & 619 & 160 & $25,85 \%$ \\
\hline Fisioterapeuta & 579 & 66 & $11,40 \%$ \\
\hline Médico & 2081 & 381 & $18,31 \%$ \\
\hline Técnico e Auxiliar de enfermagem & 6302 & 1404 & $22,28 \%$ \\
\hline Técnico de radiologia & 326 & 54 & $16,56 \%$ \\
\hline
\end{tabular}

Fonte: Ministério da Saúde, Cadastro Nacional de Estabelecimentos de Saúde (CNES), 2016 * competência jun/2016 
Figura 1 - Mapa com fluxo de encaminhamento de pacientes dentro do Estado de Tocantins nos anos de 2015 e $2016^{*}$

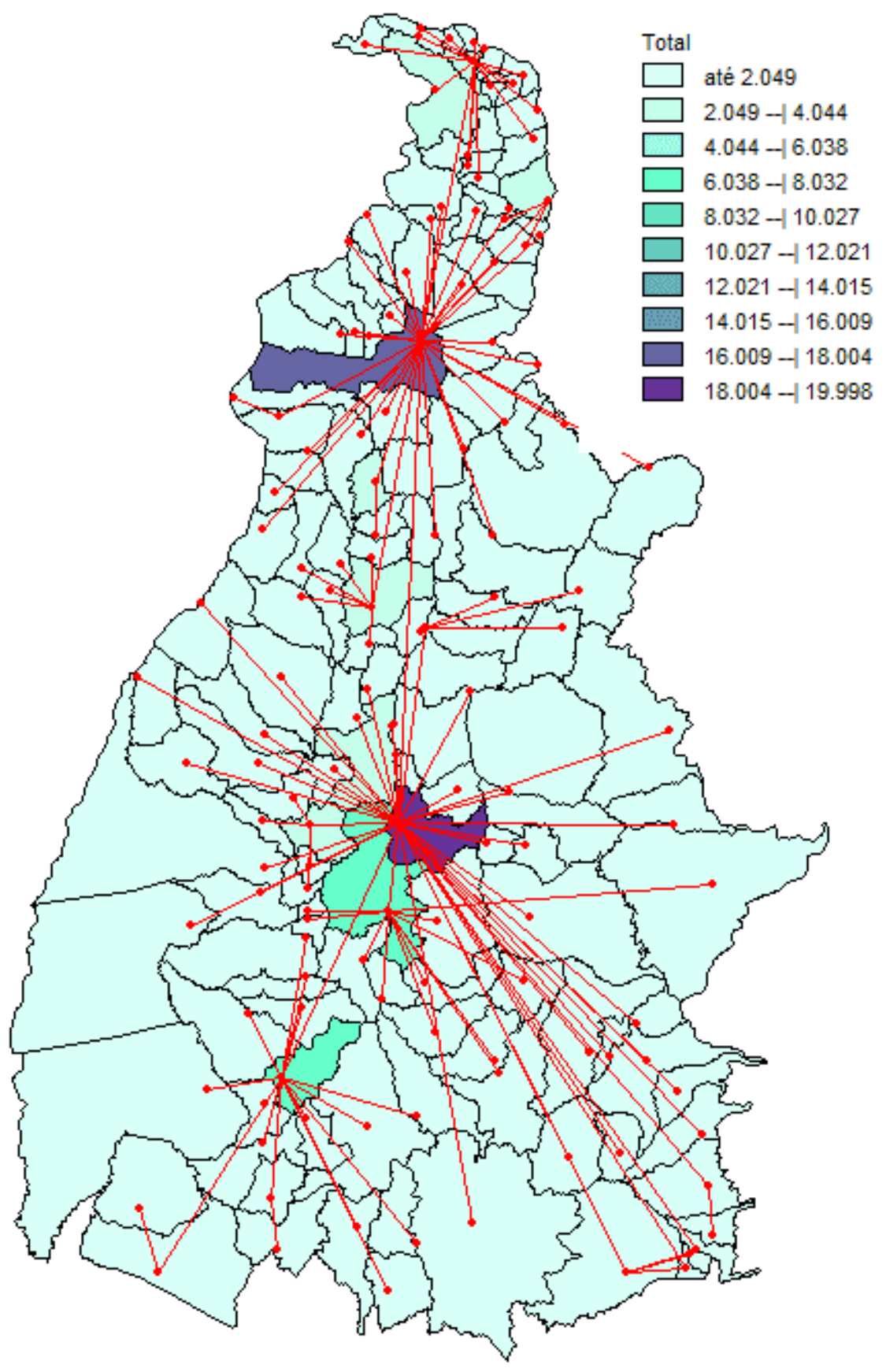

Fonte: Ministério da Saúde - Sistema de Informações Hospitalares do SUS (SIH/SUS), 2016 * até a competência jun/2016. 


\section{METODOLOGIA}

A metodologia utilizada neste trabalho consistiu no levantamento da literatura técnica existente, de legislação e trabalhos e de estudos sobre os indicadores quantitativos de pessoal em hospitais. Foram utilizados estudos de dimensionamento de pessoal publicados pela Fundação Getúlio Vargas, pela Secretaria de Estado de Saúde de São Paulo, trabalhos acadêmicos e artigos científicos, todos elencados na bibliografia que consta ao final do trabalho. Foram solicitados os dados acerca do atual dimensionamento de pessoal das unidades de saúde e realizada visitas in loco para conhecer os processos trabalho, instalações físicas e os diretores e chefes de setores foram entrevistados.

Os dados fornecidos foram confrontados com os coletados in loco assim como foi realizado um estudo acerca do dimensionamento. Para isso, considerou-se a série histórica de produção da unidade de saúde bem como a taxa média de ocupação. Foram consideradas, ainda, alguns condicionantes que interferem, diretamente, no dimensionamento do quadro de colaboradores como: política de pessoal da Organização Social, perfil dos usuários atendidos, condições de trabalho oferecidas aos colaboradores, nível de complexidades dos serviços oferecidos, grau de tecnologia incorporado pelo hospital, planta física, instalações e conservação predial.

\section{PARÂMETROS, INDICADORES E CONCEITOS UTILIZADOS}

Para a realização dos estudos e melhor compreensão dos termos técnicos nele utilizados, foi realizado um resgate teórico aceito pela literatura técnica especializada. Nesse levantamento teórico, um dos autores conceitua:

Indicadores são dados e/ou informações obtidas em realidades específicas que caracterizam essas organizações no aspecto profissionais necessários. Eles permitem fazer algumas comparações e análises em outros contextos, levando-se em conta as diferenças e semelhanças. Parâmetros são relações numéricas encontradas na quantificação de pessoas por setores, profissões face à produção. São validados e aceitos nacionalmente e são válidos para a população em análise (PICCHIAI (2009, p. 40). 
O trabalho apresentado teve como foco principal a otimização do quadro de colaboradores, inclusive, pretende, a partir da readequação do número de pessoas por setor, indicar formas alternativas de contratação para reduzir os custos. Para atingir este objetivo o uso de outros conceitos deve ser explicitado para a compreensão das fórmulas e parâmetros utilizados. Os conceitos são os mesmos adotados por Picchiai (2009) que assim os apresenta:

Assistência intensiva: pacientes graves e recuperáveis, com risco iminente de vida, sujeitos à instabilidade de funções vitais, requerendo assistência de enfermagem e médica permanente e especializada.

Assistência intermediária: pacientes estáveis sob o ponto de vista clínico e de enfermagem, requerendo avaliações médicas e de enfermagem com parcial dependência dos profissionais de enfermagem para 0 atendimento das necessidades humanas básicas.

Assistência mínima/ autocuidado: pacientes estáveis sob o ponto de vista clínico de enfermagem, mas fisicamente autossuficientes quanto ao atendimento das necessidades humanas básicas.

Complexidade: o que abrange ou encerra elementos ou partes. Os hospitais, pela sua complexidade, caracterizam-se como secundários, terciários e quaternários, de acordo com a assistência prestada, tecnologia utilizada e serviços desenvolvidos.

Hospital de pequeno porte: unidade hospitalar com até 50 leitos;

Hospital de médio porte: unidade hospitalar que possui de 51 a 149 leito;

Hospital de grande porte: unidade hospitalar que possui mais de 150 leitos;

Indicadores hospitalares: instrumentos utilizados na avaliação do desempenho hospitalar, envolvendo sua organização, recursos e metodologia de trabalho;

Informação: um dado com conhecimento; são importantes instrumentos de gerência, servindo de apoio ao planejamento e a tomada de decisão. É o ato ou efeito de informar, comunicação, indagação. Representa dados ou conhecimentos avaliados para usos específicos.

Índice: tudo aquilo o que indica ou denota alguma qualidade ou característica; relação entre valores de qualquer medida ou gradação; 
número adimensional que pode servir para a compilação de fenômenos distórios em tempos ou situações diversas.

Leito funcionante: leito disponível para ser utilizado na internação.

Leito ocupado: o leito efetivamente ocupado por um paciente.

Modelo assistencial: metodologia estabelecida na sistematização da assistência.

Modelo gerencial: compreende as atividades administrativas desenvolvidas. Modelo: permite dimensionar o quadro de funcionários do hospital de forma adequada para um atendimento satisfatório dos pacientes; de natureza normativa, procura atender as necessidades médico-hospitalares dos pacientes, e dos serviços de apoio e administração decorrentes.

Número de internações (por dia, por mês): o número de pacientes que foram internados no período considerado.

Padrão: objeto que serve de modelo à feitura de outro; modelo oficial de pesos e medidas; modelo. É o compromisso documentado utilizado em comum e repetidas vezes por todas as pessoas envolvidas.

Padronização: a atividade sistemática de uma organização, para estabelecer e utilizar padrões.

Porte: determinado pela capacidade instalada de leitos, segundo definição do Ministério da Saúde.

Saída hospitalar: É a saída do paciente da unidade de internação por alta (curado, melhorado ou inalterado), evasão, desistência do tratamento, transferência interna, transferência externa ou óbito. As transferências internas não são consideradas saídas para os cálculos das estatísticas hospitalares

Serviços: conjunto de especialidades médicas, enfermagens, psicológicas etc. oferecidas ao paciente, cujas características podem sofrer influência da entidade mantenedora, tempo de permanência, entre outras.

Taxa: razão entre as variações de duas grandezas das quais a primeira é dependente da segunda.

Taxa de ocupação (diária, mensal, por clínica, geral): uma relação percentual entre o número de leitos ocupados e o número de leitos disponíveis. 
Tempo médio de permanência: o número de dias que o paciente ficou internado, calculado pela média dos pacientes internados no mês em foco.

Variável: que pode apresentar diversos valores distintos; característica de interesse coletada (PICCHIAI, 2009, pp. 41-42).

Observa-se que a utilização da descrição na íntegra realizada pelo autor se justifica em função da complexidade do assunto estudado que merece um destaque no que diz respeito a integridade dos termos técnicos utilizados. Durante todo o trabalho, esses conceitos e parâmetros aparecem e, dessa forma, para a elaboração de um estudo que sirva para balizar o processo de decisão de uma organização é preciso garantir, no mínimo, que a comunicação seja estabelecida de forma precisa.

\section{DIAGNÓSTICO DA SITUAÇÃO ATUAL}

\subsection{HOSPITAL MUNICIPAL DE ARAGUAÍNA}

O Hospital Municipal de Araguaína - HMA é um hospital de médio porte que realiza procedimentos de baixa e média complexidade. A unidade possui 56 leitos, sendo 46 leitos clínicos pediátricos, 9 leitos cirúrgicos e 1 leito de isolamento. A unidade atende a população local e referenciada, conforme pactuado na Pactuação Programada e Integrada - PPI e é referência regional para os procedimentos de urgência, emergência e eletiva, de baixa e média complexidade, nas especialidades de oftalmologia e pediatria. O HMA comporta uma sala de estabilização, duas salas de cirurgias, dois postos de enfermagem, consultórios médicos onde funciona 0 Ambulatório de Especialidades, laboratório, cozinha, lavanderia e dependências administrativas.

Dentro da unidade também estão localizadas a sede da Central de Regulação Municipal e o serviço de Tratamento Fora do Domićlio - TFD. O hospital possui instalações físicas antigas e desgastadas. O prédio possui dois pavimentos e, no nível térreo, estão localizados os consultórios médicos, sala de estabilização, laboratório, leitos pediátricos, posto de enfermagem 1, cozinha, lavanderia e dependências administrativas. No piso superior, estão localizados o centro cirúrgico, a sala de 
recuperação pós-anestesia - RPA, os leitos cirúrgicos, o posto de enfermagem 2 e, provisoriamente, 0 arquivo do hospital. $O$ contrato de gestão firmado entre a Organização Social e o Município de Araguaína possui metas quantitativas e qualitativas a serem cumpridas mensalmente pela organização social, destacando-se:

- 300 saídas hospitalares

- 2083 consultas ambulatoriais

- 60 consultas de urgência/emergência oftalmológicas

- 30 cirurgias de pediatria

- 90 cirurgias de oftalmologia

- 1.100 procedimentos de análises clínicas

- 162 raio-x

- 31 ultrassonografias - USG

- 08 eletrocardiogramas - ECG

O parâmetro utilizado para o cálculo da meta de saídas hospitalar (internação) é de uma taxa de ocupação de $75 \%$ e média de permanência de 4,1 dias. No mês de agosto/2016 a unidade possuía o seguinte quantitativo de colaboradores: 01 diretor geral, 01 diretor técnico, 01 gerente de enfermagem, 03 médicos visitadores (prescritores), 02 médicos que atuam na urgência/emergência cirúrgica em regime de sobreaviso, 08 médicos no setor de pediatria (os médicos são contratados por plantão, totalizando 60 plantões/mês, havendo, portando, variação no número de pessoas de acordo com mês e escala). 12 enfermeiros, 45 técnicos de enfermagem 01 fisioterapeuta, 01 farmacêutico, 01 auxiliar de farmácia, 01 nutricionista, 02 assistentes social, 06 bioquímicos, 02 faturistas, 14 auxiliares de copa, 03 cozinheiros, 10 assistentes administrativo, 07 agentes de portaria, 06 auxiliares de lavanderia, 04 motoristas e 04 recepcionistas.

\subsection{UNIDADE DE PRONTO ATENDIMENTO}

A Unidade de Pronto Atendimento Anatólio Dias Carneiro é um componente préhospitalar da modalidade UPA Porte 2, conforme classificação descrita na Portaria GM/MS no 104/2014. A unidade possui 11 leitos de observação e 04 consultórios 
médicos. A UPA possui todos os equipamentos e serviços exigidos pela Portaria $\mathrm{n}^{\circ}$ GM/MS 104/2014 e, dessa forma, a unidade possui instalações físicas conservadas, demandando apenas uma repintura da parte externa. $O$ contrato de gestão prevê que a organização social deverá realizar atendimento $24 \mathrm{~h}$ e atender, mensalmente, 8.000 usuários do SUS, sendo 2.800 atendimentos pediátricos e 5.200 de clínica médica, com taxa de observação de $15 \%$ dos pacientes atendidos e $30 \%$ de pacientes encaminhados.

Além dos atendimentos, a UPA deverá realizar, mensalmente, 4.400 procedimentos de análises clínicas, 2.833 raios-x e 100 ECG. No mês de agosto/2016, a unidade possuía o seguinte quantitativo de colaboradores: 240 plantões médicos que atuam na urgência/emergência, 01 coordenadora de enfermagem, 12 enfermeiros, 28 técnicos de enfermagem, 02 assistentes social, 01 farmacêutico, 02 auxiliares de farmácia, 06 auxiliares de copa, 08 recepcionistas, 05 agentes de portaria, 01 maqueiro e 04 motoristas.

\subsection{AMBULATÓRIO DE ESPECIALIDADES}

O Ambulatório de Especialidades é integrado ao Hospital Municipal de Araguaína e possui 05 consultórios médicos, recepção climatizada e área de coleta de material para exames. Também no mês de agosto/2016 a unidade possuía o seguinte quantitativo de colaboradores: 05 técnicos de enfermagem, 01 enfermeiro, 02 atendentes de recepção (agente administrativo) e 04 recepcionistas.

\section{PROPOSTA DE DIMENSIONAMENTO}

Depois do levantamento e a realização do diagnóstico da situação atual, é chegado o momento de propor as melhorias e readequações que possam levar a uma melhor gestão dos recursos humanos empregados nas atividades citadas com a garantia de não perder a eficiência nos processos, ou porque não dizer, melhorar a eficiência destes processos por meio da realocação e otimização dos recursos disponíveis. Dessa forma, a análise dos dados coletados apresentada as possibilidades por unidade, conforme pode ser observado em seguida. 


\subsection{HOSPITAL MUNICIPAL DE ARAGUAÍNA}

Para a proposta de dimensionamento nesta unidade, foi considerada como média de permanência de internação 4 dias, conforme séria histórica do ano de 2016:

Tabela 5 - Série histórica média de permanência - 2016

\begin{tabular}{|l|l|}
\hline Mês & Média de permanência \\
\hline Janeiro & 3,7 \\
\hline Fevereiro & 3,6 \\
\hline Março & 4,2 \\
\hline Abril & 4 \\
\hline Maio & 4,2 \\
\hline Junho & 3,9 \\
\hline Julho & 4,1 \\
\hline Total & 4 \\
\hline
\end{tabular}

Fonte: Ministério da Saúde - Sistema de Informações Hospitalares do SUS (SIH/SUS), 2016

A taxa de ocupação, em 2016, variou de $33 \%$ a $49 \%$ da capacidade instalada, com uma média de $39 \%$, bem abaixo dos $70 \%$ preconizados no contrato de gestão:

Tabela 6 - Frequência de diárias faturadas e taxa de ocupação - 2016

\begin{tabular}{|l|l|l|l|}
\hline Mês & Capacidade Instalada & Produzido & Taxa de ocupação \\
\hline Janeiro & 1.650 & 592 & $35,88 \%$ \\
\hline Fevereiro & 1.650 & 684 & $41,45 \%$ \\
\hline Março & 1.650 & 593 & $35,94 \%$ \\
\hline Abril & 1.650 & 685 & $41,52 \%$ \\
\hline Maio & 1.650 & 813 & $49,27 \%$ \\
\hline Junho & 1.650 & 619 & $37,52 \%$ \\
\hline Julho & 1.650 & 547 & $33,15 \%$ \\
\hline
\end{tabular}




\begin{tabular}{l|l|l|l} 
Total & 11.550 & 4.533 & $39,25 \%$
\end{tabular}

Fonte: Ministério da Saúde - Sistema de Informações Hospitalares do SUS (SIH/SUS), 2016.

Para o setor de enfermagem, foi considerada a carga horária de 40 horas/semanais e um índice de segurança técnica de 15\% e 5,6 horas- assistenciais por paciente, por se tratar de uma unidade de saúde que realiza procedimentos de baixa e média complexidade, nos termos da Resolução COFEN no 293/2004. Quanto ao número de profissionais no setor de enfermagem, adotou-se o parâmetro apresentado por Picchiai (2009), qual seja, $20 \%$ do setor composto por enfermeiros e $80 \%$ por técnicos de enfermagem. $O$ dimensionamento é obtido aplicando-se a seguinte fórmula:

$$
\mathrm{N}^{\circ} \text { pessoas apoio técnico }=\frac{n ? \text { de pacientes }- \text { dia ambulatorial } x \text { hora }- \text { técnica } x \text { dias da semana }}{\text { jornada semanal }}
$$

Tabela 7 - Parâmetros para cálculo do número de colaboradores para o setor enfermagem - pediatria

\begin{tabular}{|l|l|}
\hline Descrição Valor & Valor \\
\hline No de leitos & 46 \\
\hline Taxa de ocupação & 0,3 \\
\hline Hora-assistencial & 5,6 \\
\hline Dias da semana & 7 \\
\hline IST & 0,15 \\
\hline Jornada semanal & $40 \mathrm{~h}$ \\
\hline
\end{tabular}

Total de pessoas para o setor de enfermagem do Posto 1 (pediatria): $18+3$ de IST, totalizando 21 pessoas, sendo 4 enfermeiras e 17 técnicas de enfermagem. Esses profissionais deverão se dividir em dois turnos de 12h. Para os leitos cirúrgicos: 
Tabela 8 - Parâmetros para cálculo do número de colaboradores para o setor enfermagem - cirurgia

\begin{tabular}{|l|l|}
\hline Descrição Valor & Valor \\
\hline № de leitos & 9 \\
\hline Taxa de ocupação & 0,39 \\
\hline Hora-assistencial & 5,6 \\
\hline Dias da semana & 7 \\
\hline IST & 0,15 \\
\hline Jornada semanal & $40 \mathrm{~h}$ \\
\hline
\end{tabular}

Total de pessoas para o setor de enfermagem do Posto 2 (cirurgia): $4+1$ de IST, totalizando 5 pessoas, sendo 1 enfermeira e 3 técnicas de enfermagem. Considerando o baixo número de cirurgias realizadas na unidade, é possível que a enfermeira responsável pelo posto 1 assuma a responsabilidade pelo posto 2. Em relação ao centro cirúrgico, a série histórica da unidade demonstra que basta manter uma equipe formada por 1 enfermeira e 2 técnicas de enfermagem, que também serão responsáveis pelo setor de esterilização. No ambulatório, tem-se por parâmetro utilizar 1 enfermeiro para cada 10 consultórios e 1 técnico para cada 3 consultórios. Para o quadro médico do hospital, deverá ser considerado o quantitativo de médicos diaristas, também denominado de hospitalista, visitador ou prescrito. Esse profissional é responsável por realizar a cobertura horizontal dos pacientes, com atuação diária.

Observa-se que, tanto Picchiai (2009) quanto Sala (2006), preconizam que o ideal é que haja 1 médico para cada 10 leitos para setores pediátrico e 1 médico para cada 6 leitos. Considerando que a taxa média de ocupação do HMA é de $39 \%$, tem- se que 2 médicos diaristas ou prescritores são suficientes para atender a demanda da unidade. A cobertura vertical da unidade é feita por médicos plantonistas, utilizandose, como parâmetro, 1 médico para cada 50 leitos.

Somente para os setores de obstetrícia é que o parâmetro utilizado é de 1 médico para 20 leitos. Para atender a demanda do HMA, é suficiente 1 plantonista para cada plantão de $12 \mathrm{~h}$, totalizando 2 médicos plantonista por dia. A unidade realiza cirurgias 
de urgência, emergência e eletiva em pediatria, nos termos do contrato de gestão firmado. Ao se analisar a série histórica de produção da unidade constata-se que o número de cirurgias, com exceção das oftalmológicas, é pequeno, podendo ser coberto por médico de sobreaviso:

Tabela 9 - Frequência de procedimentos cirúrgicos - AlH

\begin{tabular}{|l|l|l|l|}
\hline Mês & Aprovados & Rejeitados & Total \\
\hline Janeiro & 17 & 16 & 33 \\
\hline Fevereiro & 21 & 0 & 21 \\
\hline Março & 21 & 0 & 21 \\
\hline Abril & 19 & 1 & 20 \\
\hline Maio & 18 & 0 & 18 \\
\hline Junho & 14 & 0 & 14 \\
\hline Julho & 11 & 0 & 11 \\
\hline Total & $\mathbf{1 2 1}$ & $\mathbf{1 7}$ & $\mathbf{1 3 8}$ \\
\hline
\end{tabular}

Fonte: Ministério da Saúde - Sistema de Informações Hospitalares do SUS (SIH/SUS), 2016.

Portanto, 1 médico cirurgião pediátrico é suficiente para atender a demanda da unidade. Quanto aos procedimentos cirúrgicos de oftalmologia, a meta contratual é de 90 cirurgias mês, com previsão de realização de procedimentos de evisceração do olho, facoemulsificação (catarata), reconstrução de pálpebras, reconstrução de câmara anterior e pterígio. Esses procedimentos são considerados cirurgias ambulatoriais, ou seja, não há necessidade de o paciente permanecer internado na unidade. Para atender a demanda do HMA em relação às cirurgias oftalmológicas, 1 médico oftalmologista é suficiente.

Para as demais áreas do hospital, considerando o porte da unidade, basta aplicar os parâmetros apresentados por Picchiai (2009) para a obtenção do número de pessoas para cada área. No trabalho de dimensionamento, não foram considerados os serviços de laboratório, imagens, limpeza e asseio e serviço de segurança, que são 
terceirizados. Assim, tem-se que o dimensionamento do quadro de colaboradores para o Hospital Municipal de Araguaína, excluída a parte administrativa do Ambulatório de Especialidades que é integrado à unidade, é o seguinte:

Tabela 10 - Número de colaboradores por função - Hospital Municipal de Araguaína

\begin{tabular}{|c|c|c|}
\hline Função & Quantidade & Parâmetro utilizado \\
\hline Diretor Geral & 1 & \\
\hline Diretor Clínico & 1 & \\
\hline $\begin{array}{lll}\text { Diretor Administrativo } & \text { e } \\
\text { Financeiro } & & \end{array}$ & 1 & \\
\hline Gerente de Enfermagem & 1 & \\
\hline Enfermeiro & 5 & Descrito em cálculo específico \\
\hline Técnico de enfermagem & 20 & Descrito em cálculo específico \\
\hline Médico diarista & 2 & 1 para cada 10 leitos \\
\hline $\begin{array}{l}\text { Médico plantonista pediatria } \\
\text { (plantões) }\end{array}$ & 60 & 1 para cada turno de $12 \mathrm{~h}$ \\
\hline Médico cirurgião & 2 & 1 de sobreaviso por turno \\
\hline $\begin{array}{l}\text { Médico anestesiologista } \\
\text { (plantão) }\end{array}$ & 60 & 1 para cada turno de $12 \mathrm{~h}$ \\
\hline Farmacêutico & 1 & 1 para cada 50 leitos \\
\hline Auxiliar de farmácia & 2 & 1 para cada 30 leitos \\
\hline Psicólogo & 1 & 1 para cada 50 leitos \\
\hline Fisioterapeuta & 1 & 1 para cada 40 leitos \\
\hline Assistente social & 1 & 1 para cada 60 leitos \\
\hline Auxiliar de SAME & 2 & 1 para cada 30 leitos \\
\hline Faturamento & 2 & 1 para cada 40 leitos \\
\hline Auxiliar de lavanderia & 5 & $\begin{array}{l}1 \text { para cada } 10 \text { leitos - incluído a } \\
\text { UPA }\end{array}$ \\
\hline Costureira & 1 & 1 para cada 100 leitos \\
\hline
\end{tabular}




\section{Recepção}

Motorista
3

0
1 para cada 50 leitos 2 para ambulatório

Serviço deve ser terceirizado

\subsection{UNIDADE DE PRONTO ATENDIMENTO}

Para o dimensionamento do quadro de colaboradores da UPA deverão ser observadas as regras constantes na Portaria GM/MS no 104/2014 para o corpo de médicos assim como a literatura especializada para os demais colaboradores. A portaria ministerial determina que deve haver a presença de 4 médicos no período das $7 \mathrm{~h}$ às $19 \mathrm{~h}$ e 2 médicos no período das $19 \mathrm{~h}$ às $7 \mathrm{~h}$ na UPA Porte II. Contudo, 0 contrato de gestão impõe uma meta de 8.000 atendimentos mensais, o que gera, em média, 16 atendimentos por hora. Considerando que o parâmetro utilizado para consultas médicas em urgência é de 6 consultas por hora, tem-se que, num plantão de $12 \mathrm{~h}$, cada médico poderia realizar, no máximo, 72 consultas ou atendimentos. $\mathrm{A}$ meta diária é de, aproximadamente, 266 atendimentos, o que demanda a presença constante de 4 médicos por turno.

Para atender a necessidade da UPA são necessários, no mínimo, 240 plantões médicos de 12h. Para Sala (2006), a parâmetro para o dimensionamento do pessoal de enfermagem para as áreas de pronto atendimento é de 1 profissional para cada 15 atendimentos em $24 / \mathrm{h}$, sendo o corpo da enfermagem composto de $20 \%$ de enfermeiros e $80 \%$ de técnicos de enfermagem, devendo ser acrescido o IST de $20 \%$. Aplicando-se a fórmula acima, tem-se que, para o setor de enfermagem da UPA, são necessárias 21 pessoas, sendo 4 enfermeiros e 17 técnicos de enfermagem. Para as demais áreas da UPA, deve-se aplicar o critério de dimensionamento para setores de pronto socorro ou pronto atendimento. Neste estudo, não foram considerados os serviços de limpeza e asseio, segurança, serviço de imagem e laboratório, que são terceirizados.

Tabela 11 - Número de colaboradores por função - Unidade de Pronto Atendimento 


\begin{tabular}{|l|l|l|}
\hline Diretor Geral & 1 & \\
\hline Enfermeiro & 4 & Por turno \\
\hline Técnico de enfermagem & 17 & Por turno \\
\hline Enfermeiro acolhimento & 2 & 1 para cada turno \\
\hline Médico plantonista (plantões) & 240 & 4 para cada turno de 12h \\
\hline Farmacêutico & 1 & 1 para cada 50 leitos \\
\hline Auxiliar de farmácia & 2 & 1 para cada 30 leitos \\
\hline Recepção & 5 & 3 para o diurno 2 para o noturno \\
\hline Motorista & 4 & 2 para cada turno \\
\hline Agente de portaria & 4 & 2 para cada turno \\
\hline Auxiliar de copa & 4 & 2 para cada turno \\
\hline Motorista & 0 & Serviço deve ser terceirizado \\
\hline
\end{tabular}

\subsection{AMBULATÓRIO DE ESPECIALIDADES}

O Ambulatório de Especialidades, apesar de estar inserido na estrutura do Hospital Municipal de Araguaína, possui dinâmica própria e deve ser analisado de forma separada. A meta contratual são 2.250 consultas por mês divididas em diversas especialidades. $O$ ambulatório funciona de segunda a sexta-feira, das $7 \mathrm{~h}$ às $19 \mathrm{~h}$ e aos sábados das $7 \mathrm{~h}$ às $12 \mathrm{~h}$. $\mathrm{O}$ Ambulatório de Especialidades possui 5 consultórios médicos, com acesso à sala de coleta de material para exames e acesso para exames de radiologia e demais dependências do hospital. Pelo número elevado de consultas médicas, a contratação de médicos deverá ser feita por produção, não existindo, assim, a necessidade de estimar o número de profissionais para esse setor. Em relação ao pessoal de enfermagem, Picchiai (2009) e Sala (2006) preconizam que é necessário 1 enfermeiro para cada 10 consultórios e um técnico de enfermagem para cada 3 consultórios. Para a recepção, estima-se que o tempo dispensado para cada paciente é de 12 minutos. Para o cálculo do número de recepcionistas e pessoal de apoio aplica-se a seguinte fórmula, segundo Picchiai (2009):

\footnotetext{
$\mathrm{N}^{\circ}$ pessoas apoio técnico $=\frac{n^{0} \text { de pacientes-dia ambulatorial } x \text { hora-técnica } x \text { dias da semana }}{\text { jornada semanal }}$
} 
Considerando que 12 minutos são 0,2 horas-técnica e que, em média, são atendidos 113 pacientes diariamente, em 5,5 dias da semana e com jornada de $44 \mathrm{~h}$ semanais, tem-se que são necessárias 3 pessoas para trabalhar na recepção.

Tabela 12 - Número de colaboradores por função - Ambulatório Médico

\begin{tabular}{|l|l|l|}
\hline Função & Quantidade & Parâmetro \\
\hline Médico especialista & - & Contratação por produção(consulta) \\
\hline Enfermeiro & 1 & 1 para cada 10 consultórios \\
\hline Técnico de enfermagem & 2 & 1 para cada consultório \\
\hline Recepcionista e apoio & 3 & 0,2 hora-técnica para cada paciente \\
\hline
\end{tabular}

\subsection{QUADRO SÍNTESE}

Para melhor compreensão da situação proposta, segue uma explanação do quadro síntese a fim de auxiliar na compreensão do dimensionamento proposto na estrutura organizacional, conforme apresentado.

Tabela 13 - Quadro comparativo - Hospital Municipal de Araguaína

\begin{tabular}{|l|l|l|l|}
\hline Função & $\begin{array}{l}\text { Quantidade } \\
\text { atual }\end{array}$ & $\begin{array}{l}\text { Quantidade } \\
\text { recomendada }\end{array}$ & $\begin{array}{l}\text { Quantidade } \\
\text { Mínima }\end{array}$ \\
\hline Diretor Geral & 1 & 1 & 1 \\
\hline Diretor Clínico & 1 & 1 & 1 \\
\hline $\begin{array}{l}\text { Diretor Administrativo e } \\
\text { Financeiro }\end{array}$ & 1 & 1 & 1 \\
\hline Gerente de Enfermagem & 1 & 1 & 1 \\
\hline Enfermeiro & 12 & 5 & 5 \\
\hline Técnico de enfermagem & 45 & 20 & 18 \\
\hline Médico diarista & 3 & 2 & 2 \\
\hline $\begin{array}{l}\text { Médico plantonista } \\
\text { pediatria (plantões) }\end{array}$ & 60 & 60 & 60 \\
\hline Médico cirurgião & 2 & & 1 \\
\hline
\end{tabular}




\begin{tabular}{|l|l|l|l|}
\hline $\begin{array}{l}\text { Médico anestesiologista } \\
\text { (plantão) }\end{array}$ & 60 & 60 & 30 \\
\hline Farmacêutico & 1 & 1 & 1 \\
\hline Auxiliar de farmácia & 2 & 2 & 2 \\
\hline Psicólogo & 1 & 1 & 1 \\
\hline Fisioterapeuta & 1 & 1 & 1 \\
\hline Assistente social & 1 & 1 & 1 \\
\hline Auxiliar de SAME & 2 & 2 & 2 \\
\hline Faturamento & 2 & 2 & 2 \\
\hline Auxiliar de lavanderia & 5 & 5 & 5 \\
\hline Costureira & 1 & 1 & 1 \\
\hline Recepção & 4 & 3 & 3 \\
\hline Motorista & 4 & 0 & 0 \\
\hline
\end{tabular}

Observa-se, no quadro acima, que o setor de enfermagem é o que atualmente possibilita a maior intervenção tendo em vista que, por exemplo, a quantidade de técnicos de enfermagem é quase três vezes maior que o mínimo permitido, de acordo com os parâmetros apresentados. Dessa forma, é possível fazer uma diminuição expressiva deste quadro sem a perda da qualidade na prestação do serviço nesta área.

Tabela 14 - Quadro comparativo - Unidade de Pronto Atendimento

\begin{tabular}{|c|c|c|c|}
\hline Função & $\begin{array}{l}\text { Quantidade } \\
\text { atual }\end{array}$ & $\begin{array}{l}\text { Quantidade } \\
\text { recomendada }\end{array}$ & $\begin{array}{l}\text { Quantidade } \\
\text { Mínima }\end{array}$ \\
\hline Diretor Geral & 1 & 1 & \\
\hline $\begin{array}{l}\text { Coordenador de } \\
\text { Enfermagem }\end{array}$ & 1 & 1 & 1 \\
\hline Enfermeiro & 12 & 4 & 4 \\
\hline $\begin{array}{ll}\text { Técnico } & \text { de } \\
\text { enfermagem } & \end{array}$ & 28 & 17 & 17 \\
\hline
\end{tabular}




\begin{tabular}{|l|l|l|l|}
\hline $\begin{array}{l}\text { Enfermeiro } \\
\text { acolhimento }\end{array}$ & 2 & 2 & \\
\hline $\begin{array}{l}\text { Médico plantonista } \\
\text { (plantões) }\end{array}$ & 240 & 240 & 180 \\
\hline Farmacêutico & 1 & 1 & 1 \\
\hline Auxiliar de farmácia & 2 & 2 & 2 \\
\hline Recepção & 8 & 5 & 4 \\
\hline Motorista & 4 & 0 & 0 \\
\hline Agente de portaria & 5 & 4 & 4 \\
\hline Auxiliar de copa & 6 & 4 & 4 \\
\hline
\end{tabular}

Sem dúvida, um dos setores mais complexos para se propor um redimensionamento de pessoal é a Unidade de Pronto Atendimento, em função da portaria específica que rege a unidade e previamente determina a quantidade mínima de pessoal. Mesmo assim, nota-se que o quadro de enfermeiros atual de 12 profissionais pode, perfeitamente, ser reduzido a um terço desta quantidade. A equipe de técnicos de enfermagem também pode perder 11 funcionários, e, mesmo assim, conseguirá cumprir com a demanda instalada na unidade.

Tabela 15 - Quadro comparativo função - Ambulatório Médico

\begin{tabular}{|l|l|l|l|}
\hline Função & $\begin{array}{l}\text { Quantidade } \\
\text { atual }\end{array}$ & $\begin{array}{l}\text { Quantidade } \\
\text { recomendada }\end{array}$ & $\begin{array}{l}\text { Quantidade } \\
\text { Mínima }\end{array}$ \\
\hline $\begin{array}{l}\text { Médico Especialista } \\
\text { Enfermeiro }\end{array}$ & 1 & - & - \\
\hline $\begin{array}{l}\text { Técnico de } \\
\text { Enfermagem }\end{array}$ & 4 & 1 & 1 \\
\hline $\begin{array}{l}\text { Recepcionista e } \\
\text { apoio }\end{array}$ & 4 & 2 & 2 \\
\hline
\end{tabular}

Por último, a síntese do ambulatório médico propõe uma redução de $50 \%$ em sua equipe de técnicos de enfermagem, sendo essa a intervenção mais impactante para o departamento. Assim sendo, por se tratar de uma síntese dos dados já amplamente 
discutida anteriormente, faz-se desnecessário a reanálise dos mesmos, tendo em vista que a intenção é, exatamente, trazer, a partir de um único gráfico, informações inerentes à situação atual, às recomendações e à quantidade mínima aceitas para cada setor.

\section{CONCLUSÃO}

Durante a elaboração do estudo, pode-se perceber que existe uma ociosidade de grande parte dos recursos humanos empregados nas três unidades de serviços. Um dos principais objetivos era saber se era possível medir, com precisão, um serviço tão complexo quanto o da área da saúde. E neste, o objetivo foi amplamente alcançando, levando em consideração a literatura técnica existente que possibilitou a aplicação de fórmulas de cálculos de produção para cada área e setor da saúde. Feitas as medições necessárias da produtividade, bem como de posse dos dados coletados, ficou fácil comprovar que, ao utilizar os cálculos, observando sua aplicação na íntegra, os setores que demonstram excesso de mão-de-obra disponível são passíveis de redução para os patamares próximos aos limites estabelecidos sem perda da qualidade do serviço prestado.

A estimativa de dimensionamento de pessoal feita neste trabalho considerou a produção das unidades e as informações fornecidas pela Organização Social que atua naquele município. Os números apresentados para a área de enfermagem são considerados de forma horizontal, devendo a escala de enfermagem ser feita segundo o regime de plantão adotado na unidade $(12$ x 36) ou sistema de contratação fixo (30 ou $40 \mathrm{~h}$ semanais). Não foram consideradas para o estudo as especificidades de convenções ou acordos coletivos de trabalhos bem como os planos de cargos e remuneração da Organização Social. Por fim, o quantitativo apresentado refere-se a um número total de colaboradores, devendo haver divisões do número por período de trabalho (diurno e noturno, dia de semana e fim de semana). 


\section{REFERÊNCIAS}

BARBOSA, N. B., ELIAS P. E. M. As organizações sociais de saúde como forma de gestão público/ privado. Cienc Saude Colet, v. 15, n. 5, p. 2483-2495, 2010.

BORBA, V. R. Administração hospitalar: princípios básicos. 3 ed. São Paulo: CEDAS, 1991.

BRASIL. Portaria no 104 de 15 de janeiro 2014. 2014. Disponível em http://bvsms.saude.gov.br/bvs/saudelegis/gm/2014/prt0104_15_01_2014.html. Acesso em 16. Mar. 2017.

MALAGÓN-LODOÑO, G. Administração Hospitalar. 3. ed. Rio de Janeiro: Guanabara Koogan, 2014.

PICCHIAI, D. Parâmetros e indicadores de dimensionamento de pessoas em hospitais. Pesquisas e Publicação da Escola de Administração de Empresas de São Paulo. São Paulo: FGV, 2009.

RIBEIRO, P. S. O que é Organização Social? Brasil Escola. 2017. Disponível em http://brasilescola.uol.com.br/sociologia/o-que-organizacao-social.htm. Acesso em: 16. Mar. 2017.

SALA, A (org). Parâmetros para o planejamento e dimensionamento da força de trabalho em hospitais gerais. Secretaria de Estado da Saúde de São Paulo. São Paulo, 2006.

2. CNES - Cadastro Nacional de Estabelecimentos de Saúde.

Enviado: Junho, 2019.

Aprovado: Novembro, 2019. 